MS. AILSA MUNNS (Orcid ID : 0000-0002-8489-769X)

Article type : Original Article

\title{
Aboriginal parent support: A partnership approach
}

\section{Authors}

Ailsa Munns, Bachelor Applied Science (Nursing), Master Nursing, PhD Candidate.

Lecturer, School of Nursing, Midwifery \& Paramedicine, Faculty of Health Sciences, Curtin University, Perth, Western Australia.

Christine Toye, PhD, Associate Professor, Older Persons' Health Care, School of Nursing, Midwifery \& Paramedicine, Faculty of Health Sciences Curtin University, Perth, Western Australia.

Desley Hegney, Dip Nurs Edu, B.A.(Hons1), PhD, FCNA. Professorial Research Fellow, Research Division, Central Queensland University, Hon. Professor, School of Nursing and Midwifery, University of Southern Queensland; Adjunct Professor, School of Nursing, University of Adelaide

Marion Kickett, PhD. Professor, Director of Centre for Aboriginal Studies, Curtin University, Perth, Western Australia.

Rhonda Marriott, PhD, Professor, Aboriginal Health and Wellbeing, School of Psychology and Exercise Science, Murdoch University, Perth, Western Australia; Chair in Nursing, Maternal \& Newborn Health, Aboriginal Health \& Wellbeing, Nursing and Midwifery Office, Department of Health Western Australia.

Roz Walker, PhD, Associate Professor, Head, Aboriginal Maternal Health and Child Development, and previously Chief Investigator, NHMRC, Centre for Research Excellence in Aboriginal Health and Wellbeing, Telethon Kids Institute, Subiaco, Western Australia; University of Western Australia, Crawley, Western Australia.

Corresponding author:

Ailsa Munns

School of Nursing, Midwifery \& Paramedicine

Curtin University

GPO Box U1987, Perth, Western Australia, 6845

Phone: 0892662209

This article has been accepted for publication and undergone full peer review but has not been through the copyediting, typesetting, pagination and proofreading process, which may lead to differences between this version and the Version of Record. Please cite this article as doi: 10.1111/jocn.13979

This article is protected by copyright. All rights reserved. 
Email: A.Munns@curtin.edu.au

Acknowledgements

Our thanks are extended to the Peer Support Workers, Project Coordinator and Education Support Officer (Ngala) who generously gave their time and support to the parent support project. Thanks are also given to Ngala management.

This work was supported by the Centre for Research Excellence in Aboriginal Health \& Wellbeing at Telethon Kids and the Western Australian Nurses Memorial Charitable Trust.

\begin{abstract}
Aims and objectives

This study was positioned within a larger action research study relating to a peer-led Aboriginal home visiting parent support program in an urban Western Australian setting. The aims for this study component were to identify program elements, exploring participants' perceptions of the program's suitability, feasibility, acceptability and effectiveness to inform program model recommendations and add to the body of knowledge on effective Aboriginal peer-led program models.
\end{abstract}

\title{
Background
}

The ability of Aboriginal parents to develop positive family environments is crucial, with parent support needing to be reflexive to local needs and socio-cultural influences. Culturally appropriate service provision needs meaningful and acceptable strategies.

\section{Design}

This study was situated within a critical paradigm supporting Participatory Action Research methodology, using Action Learning Sets as the participant engagement and data collection setting.

This article is protected by copyright. All rights reserved. 


\section{Methods}

Within ten Action Learning Sets, focus group interviews were carried out with Aboriginal peer support workers, a non-Aboriginal parent support worker, an Aboriginal program coordinator, an Aboriginal education support officer and non-Aboriginal program managers, $(\mathrm{n}=8)$, and individual interviews with parents $(\mathrm{n}=2)$ and community agencies $(\mathrm{n}=4)$. Data were analysed using thematic analysis.

\section{Results}

Five themes were derived from peer support worker and community agency cohorts: Peer support worker home visiting skills; Responding to impacts of social determinants of health; Client support and engagement; Interagency collaboration, and Issues addressing program sustainability. Parent responses augmented these themes.

\section{Conclusions}

Participants identified five key elements relating to peer-led home visiting support for Aboriginal parents. These are uniquely placed to inform ongoing program development as there is little additional evidence in wider national and international contexts.

\section{Relevance to Clinical Practice}

Engagement with communities and peer support workers to develop culturally relevant partnerships with Aboriginal families is integral to contemporary child health practice. Ongoing nurse support is needed for peer support worker role development.

Indigenous Australian peoples are people who identify as Aboriginal or Torres Strait Islander. Respectfully, throughout this paper, they will be described as Aboriginal. 


\section{Keywords}

Aboriginal, Action Learning, Community Nursing, Cultural Issues, Home Visits, Models of Care, Parenting, Qualitative Approaches

\section{What does this paper contribute to the wider global clinical community?}

- Culturally relevant community child health practice with Aboriginal families and their children in the early years can be enhanced through home visiting partnerships with peer support workers.

- Key elements contributing to effective strategies include peer support worker home visiting skills, responding to impacts of social determinants of health, client support and engagement, interagency collaboration, and issues addressing program sustainability.

\section{Introduction}

The early years of life are considered to be the most important developmental phase, critical for healthy physical, emotional and social outcomes throughout the life course (WHO, 2015). Positive family functioning is integral to children's wellbeing. Strengthening the capacity of parents to proactively influence their children's health and development substantially contributes to a positive lifelong outcomes. In particular, support for Aboriginal families during these early years is significant because of the considerable proportion of Aboriginal children experiencing ongoing disadvantage across a range of health and wellbeing measures (Commissioner for Children and Young People, Western Australia, 2015). The ability of families to support their children, maintaining positive parenting practices and children's developmental progress, is underpinned by comprehensive, flexible community based child and family health services (Shepherd \& Walker, 2008, Author A et al., 2016). This research 
investigated the suitability, feasibility and acceptability and the necessary elements of a peerled home visiting intervention as a way to support Aboriginal families and children in an urban area of Western Australia. The results will inform recommendations for a sustainable program model in this area and to add to the body of knowledge on effective Aboriginal peerled program models.

\section{Background and Literature Review}

In presenting the need for parent support for Aboriginal families, it is important to recognise the strengths in many Western Australian Aboriginal family environments where children have culturally nurturing approaches to their care and development (Wilkes, 2014). However, it is also recognised, both nationally and internationally, that, in countries with a colonial history such as North America, New Zealand and Australia, there is a high burden of poor health and wellbeing experienced by Indigenous families and communities. Aboriginal people's health status is persistently below that of their country's whole population and access to resources and opportunities is adversely affected by historical and contemporary social determinants of health (Zubrick et al., 2014; Freemantle et al., 2007; AIHW, 2012). Unfortunately, factors such as colonisation, dispossession, institutional racism and poverty present ongoing and cumulative challenges to the role of Australian Aboriginal parents in maintaining strong families (Gray et al., 2007; Milroy, 2014; Walker \& Shepherd, 2008). It is therefore important that these multidimensional historical, environmental, sociocultural and economic influences impacting on family functioning (Walker $\&$ Shepherd, 2008) are taken into consideration when developing parent support programs. Of note is their intergenerational effects on parents' feelings of self efficacy and empowerment (Bowes \& Grace, 2014, Milroy et al., 2014). A positive sense of social and emotional wellbeing 
underpins the capacity to develop enhancing and nurturing environments for children (Australian Government, Department of Health, 2013) which are linked to feelings of cultural, family and community connectedness (Government of WA, DoH, 2015). Parents need culturally relevant support services that are accessible and acceptable to strengthen their families' growth and development (Milroy et al., 2014).

Without supportive interventions, childhood adversity has well established associations with toxic and chronic stress, leading to compromised life-course trajectories. Risk factors are complex, wide ranging and long standing, including poverty, recurrent physical and/or emotional abuse, chronic neglect, perinatal depression and family violence (Shonkoff et al., 2009; Marriott \& Ferguson-Hill, 2014). This kind of stress disrupts brain architecture, with cumulative changes inducing allostatic load, where the impact of chronic stress alters physiological and psychosocial health and wellbeing. People's behaviours shift from adaptive to maladaptive responses, frequently displayed as anger, frustration and feelings of disempowerment. There may be increased use of alcohol and illicit substances (McEwen, Nasveld, Palmer \& Anderson, 2012). These behaviours compromise developmental progress which is central to successful lifelong psychosocial and emotional adjustment and physical health (Garner, 2013; Shonkoff et al., 2009; Rogosch et al., 2011). Adversity in a child's early years thus poses risks of embedding lifelong vulnerabilities with outcomes relating to family, community and politically based social determinants of health. Modifying the environments in which young children live will potentially ameliorate adversity (Bowes \& Grace, 2015, Shonkoff et al., 2009), a fact that highlights the need for proactive family and community based early interventions.

With families being the primary context for children's healthy development, the ability of Australian Aboriginal parents to develop family stability and positive relationships is crucial. Programs to support parents in the early years of children's lives are designed to enhance 
parent-child attachment. Additionally, they aim to increase parents' knowledge of child development and their capabilities and self-efficacy in parenting competencies, thereby promoting positive coping approaches to parenting challenges (Bowes \& Grace, 2014, Sanders et al., 2000, Mildon \& Polimeni, 2012). A systematic review by Dudgeon et al. (2014) on effective strategies to promote Indigenous wellbeing identified seven parenting education programs designed specifically for Aboriginal families in Australia, with suggestions that they have greatest effectiveness as strength-based universal primary prevention approaches when including Aboriginal support workers. There are varying support strategies, with programs offered in a number of formats including groups and individual approaches within settings such as clinics, community venues and homes (Mildon \& Polimeni, 2012). Evidence suggests that assistance for parents is most effective when reflexive to local needs, taking into account social, cultural and political influences and acknowledging familial and language groups (Author B, 2010). Recognition of both barriers and enhancing factors establishes a strengths-based approach, enabling elements of parental resilience in the form of strengths, abilities and capabilities to be incorporated into program development, also promoting active engagement and positive outcomes for parents and children (Department of Communities, Child Safety and Community Services, 2013; Tehan \& McDonald, 2010; Grant \& Cadell, 2009; Shepherd \& Walker, 2008). Price-Robertson (2010) further postulates that this approach ameliorates the perception of vulnerability for young parents so that they feel able to achieve positive parenting outcomes with appropriate, sustainable support. Meeting the needs of local Aboriginal parents is through a holistic approach, actively engaging in collaborative partnerships with parents and community support groups to identify unique strengths and foster strategies that are authentic and of mutual benefit.

This article is protected by copyright. All rights reserved. 
A review of successful Indigenous programs in communities by Bowes and Grace (2014) confirms the importance of adopting a strengths-based, family-centred approach. Of note is the necessity for program flexibility and sustainability of funding and resources, along with modifications to suit the local community's context and specific requirements, which inform effective collaborative models of service. Other key elements for successful program implementation include: the employment, training and support of local community members to enable cultural guidance in program development and active involvement in service delivery, realistic expectations and requirements that accommodate community issues, avoidance of conflict and creation of a safe, culturally secure service environment for Indigenous workers. Effective culturally competent non-Indigenous program staff are those who connect with the community, "value the trust and respect placed in them, and are able to let go of rigid western notions of time" (Bowes \& Grace, 2014, p. 3).

Central to development of enhancing strategies for Australian Aboriginal parents is the recognition that, both internationally (Isajiw, 1999; Preston, 2002; Neckowaya et al., 2007), and nationally (Dudgeon \& Ugle, 2014), Aboriginal cultures cannot be viewed as homogeneous. There are considerable different characteristics specific to geographical locations and social networks that need to be taken into account in program development. In Australia, notwithstanding the recognition that there is no single set of Aboriginal parenting practices, there are a number of significant commonalties influencing parenting across cultural contexts, including the value of extended family and social relationships in childrearing (Heath et al., 2011). Of additional importance is the need for acknowledgement and incorporation of Aboriginal worldviews of health and wellbeing, where cognitive, perceptual and affective awareness of these beliefs are developed and affected through social interactions and historical and cultural influences. Researchers and program developers need to work with Aboriginal parents, support workers and communities to facilitate approaches 
and advances that are reflective of local culture, belief systems and models of care (Hart, 2010). Cultural appreciation and understanding of parenting within reflexive models of practice are needed for non-Aboriginal health professionals engaged with Australian Aboriginal families and support workers in order to foster strong relevant family support systems (Shepherd \& Walker, 2008; Author A et al., 2017).

The importance of authentic and relevant parent support are key elements of program success. Consistent with Author A \& B (2015) and Heath et al. (2012), Price-Roberston and McDonald (2011, p. 1) proposed implementation strategies that can be used to strengthen Aboriginal parents, including:

- working with (rather than working “on”) Aboriginal parents and communities;

- ensuring services are culturally competent;

- focusing on attracting and retaining the right staff;

- cultivating supportive community networks and relationships; and

- adopting an action research approach.

A key finding from a mixed methods Australian research evaluation on how to strengthen Indigenous families and communities highlighted the importance of the quality of and relationships between project staff and the communities when working to achieve positive project outcomes (Scougall, 2008). The employment of local Aboriginal support workers was considered crucial as they brought with them established community networks and understanding of local cultural issues, meaning that clients were usually able to discuss family issues with less hesitation (Scougall, 2008). An evaluation of an Aboriginal peer-led family support program in the remote Kimberley region of Western Australia had similar findings (Author B, 2010; Author A et al., 2016). 
Across all Australian states and communities, these elements provide opportunities for Aboriginal parents, support workers their communities to work in partnership across dynamic cultural contexts. In contrast, there are factors impeding effective program implementation, including lack of appropriate infrastructure, human resource management issues including high incidences of staff burnout and turnover, challenging social environments with low levels of trust, participation and efficacy along with high levels of anxiety, disempowerment and mobility. Complex or "wicked" characteristics and societal issues impacting on many Aboriginal families for which there may be inadequate resources are confounding factors (Walker \& Shepherd, 2008). The National Empowerment Program conducted in thirteen sites in Australia identified a number of effective strength-based responses to address problems in Indigenous communities (Dudgeon et al., 2014). In a similar Australian research evaluation on family support, it was noted that having Aboriginal support workers closely connected to a community could pose challenges where community or family conflicts arose.

Recommendations for culturally appropriate services were in the primary health care context of being non-threatening, informal and low cost, being flexible in location and manner of assistance, and offering services away from formal, institutional settings such as a client's home (Flaxman et al., 2009). Reducing adverse features of parent support strategies and strengthening enhancing characteristics are challenging for program facilitators and support workers. Client centred approaches to address their self-identified needs and preferences for culturally appropriate service provision positions Aboriginal peer-led home visiting support as an appropriate form of engagement. However, this support needs further exploration to assess program processes issues, acceptable strategies and participant meaningfulness, along with parenting and children's developmental outcomes.

In 2012, a Western Australian family support agency highlighted the need for Aboriginal parent support in a low socioeconomic urban community, following which a collaboration 
between a community child health nurse researcher experienced in the development of Aboriginal parent support programs was formed. An action research project facilitated by the non-Aboriginal researcher in partnership with an Aboriginal program coordinator, Aboriginal education support officer, Aboriginal peer support workers (PSWs) and community agencies supporting Aboriginal families in the local area was undertaken over a 13 month period from July 2013 to November 2014. Critical reflection on the background to the current program has been previously described along with challenges and adaptations to implementation of methods (Author A et al., 2016, 2017).

\section{Study Methodology}

\section{Aim}

In partnership with the urban community, the aim of the overall study was to investigate the self-perceived suitability, feasibility and acceptability of parent support and inform a model for a culturally secure, peer-led, home visiting model for Aboriginal families and children within this Western Australian community.

\section{Research question}

Broad research questions may be specified as study aims or goals, indicating the purpose for the inquiry rather than being stated as questions (Agree, 2009). As such, the methodological aims for this study component were to:

- Identify and examine the elements required to deliver a culturally secure Aboriginal led home visiting child health parent support program;

This article is protected by copyright. All rights reserved. 
- Explore the self-perceived suitability, feasibility, acceptability and effectiveness of a culturally secure Aboriginal led home visiting child health parent support program; and

- Inform a model for a culturally secure Aboriginal led home visiting child health parent support program in this urban area and add to the body of knowledge on effective peer-led home visiting program models.

\section{Ethical considerations}

Approval for this research was gained from the Western Australian Aboriginal Health Ethics Committee, the Curtin University Human Research Ethics Committee, and the family support agency's research committee. Written consent for participation in the research was obtained from each participant following provision of information sheets.

\section{Research paradigm, Methodology and Methods}

This study was situated within a critical paradigm supporting Participatory Action Research (PAR) methodology, using focus groups within Action Learning Sets (ALSs) as the participant engagement and data collection setting. Elaboration of these, along with strategies for research rigour, have been previously described (Author A et al., 2016, 2017).

Demographic information were collected from all cohorts. Some anticipated data were not achievable due to personal and cultural sensitivities, services not being offered, and agency and PSW record keeping processes. For example, within the PSW group, PSW ages, specific numbers of home visits and referrals, and exemplars of brief health interventions were not available. For parents, specific numbers of home visits per family were not reliable as many visits were opportunistic and away from the home setting.

This article is protected by copyright. All rights reserved. 


\section{Participants}

There were three participant cohorts with a total of 14 respondents, these being the family support agency's program staff consisting of Aboriginal PSWs, a non-Aboriginal parent support worker, an Aboriginal program coordinator, an Aboriginal education support officer and non-Aboriginal program managers; in addition to Aboriginal client families and Aboriginal and non-Aboriginal community agency staff.

During the progress of the research, two to four PSWs, the program coordinator, one nonAboriginal support worker for four months, one program support educator for three months, five participants from four community agencies and two mothers contributed to the ongoing program development. PSWs were able to engage with 164 families. It was proposed to interview eight to ten families. However only two parents were available due to social and family issues, and moving from the area (Rosenthal \& Khalil, 2010; Zubrick et al., 2014). Feedback from families was also reported by PSWs, indirectly contributing to program development. Ten ALSs were facilitated over the 13 month period, with PSWs participating in every set. Clients and community agencies contributed in ALSs one, four, seven and ten. Other program staff contributed intermittently over the 13 month period.

\section{Data collection}

During focus groups with PSWs plus community agency staff, semi structured group interview processes were undertaken by the researcher (Cohen \& Crabtree, 2006). Individual unstructured interviews were conducted with Aboriginal parents using yarning as an interview technique (Bessarab \& Ng'andu, 2010; Bessarab, 2012), the value of which has been previously described in Author A et al. (2016, 2017). Yarning was also intermittently used to collect data from PSWs and a community agency Aboriginal staff member. 
Interviews lasted approximately three hours for PSWs, program coordinator and program support educator, one hour for community agencies and twenty to thirty minutes for parents. All the data were digitally recorded and transcribed verbatim. Additionally, observational field notes were documented by the researcher to provide additional data.

\section{Data Analysis}

Demographic data were analysed manually and will be described elsewhere. Thematic analysis, which is a flexible analytical strategy utilised across a range of epistemologies and research questions, was used to analyse qualitative data from all three cohorts. Following data transcription, data were read and coded according to significant characteristics. Themes were developed from the emerging codes, which identified important aspects of the data in relation to the research question, representing patterned responses and meanings (Table 1) (Braun \& Clarke, 2006). The themes emerged as categories for analysis (Fereday \& Muir-Cochrane, 2006).

\section{Table 1 here}

\section{Results}

There were five themes derived from the two program staff and community agency cohorts. Peer support worker home visiting skills; Responding to impacts of social determinants of health; Client support and engagement; Interagency collaboration; and Issues addressing program sustainability. Sub-themes were also generated. Following the small number of parent interviews, these data will be presented to augment relevant themes (Table 2).

\section{Table 2 here}

This article is protected by copyright. All rights reserved. 


\section{Peer support worker home visiting skills}

This theme comprised two sub-themes: Peer support worker education and training needs; and Peer support worker attributes and strategies.

\section{Peer support worker education and training needs}

A key feature of PSW's ability to successfully engage with clients was provision of ongoing, regular education and training, including learning the process of visiting and working in partnership with families, peers and mentors. The emphasis was on having empathy for parents' individual situations, providing praise for their parenting efforts, encouraging community engagement and referring to appropriate professional support. Learning the process of visiting clients was developed over time, with PSWs gradually gaining knowledge of early years' issues along with practical skills of parent engagement.

After you do your first one (visit) you have an idea and then the next one you get like more of an idea then the next one after that... you want to sound professional. (PSW)

PSWs valued training sessions on a variety of topics that were offered by the employing family support agency which supported their skill development and confidence.

...they are good to go to them training 'cause you're learning all different things and like it's building your confidence up. Like for speaking things you know what you're speaking about. $(P S W)$

I just like to do all different training. So we know all different things because yeah everyone's different...it's good in case that ever comes up then we have a bit of skills in that. (PSW)

Mentorship was important. Observing and listening alongside Aboriginal and non-Aboriginal program staff and peers developed PSW confidence for making introductory phone calls and home visits.

This article is protected by copyright. All rights reserved. 
... we have a bit of a chat about it (visit) afterwards, what worked, what didn't work, what they observed, what they heard that I didn't. A little bit of follow through like that and what will you do for the second, the next visit and you know a little bit of prep time to talk about that. (Program staff member)

I sit back and listen to (PSW) when she's ringing up. (PSW)

It's just a learning process with (mentor). I'm just getting comfortable engaging and sitting and just listening to the clients and what their parenting issues. (PSW)

Additionally, the Education Support Officer was able to offer extra learning support between the action learning sets, which enhanced continuous learning and development.

So basically just getting them prepared to start, just to think about you know how they're going to work that week and deal with their clients and what they need to do. If there's any resources that they might need and things like that. Support them in that role and then debriefing after each session. So basically what's the goal for that visit, what are we wanting to achieve on that visit. (Education Support Officer)

Exploring how to raise sensitive issues such as smoking, and child safety was identified as being important for PSWs to observe and learn, as PSWs did not want to be seen as confronting to their clients and reduce the development of trust.

I haven't really been in that in that environment to bring it (smoking) up. But I wouldn't know, I guess I'd learn off (Program staff member) 'cause you know she has been in all different situations. (PSW)

The cord was just hanging and the TV was right on the corner of the table and (Program staff member) explaining that to fix that. You can just go in there and just make it a conversation and then make it into a, not like a probing question. (PSW)

This article is protected by copyright. All rights reserved. 


\section{Peer support worker attributes and strategies}

PSW visits to families were both planned and opportunistic. Planned visits were undertaken at parents' homes and nominated venues in addition to community agencies during their parent activities. Many booked home visits required multiple attempts by PSWs to contact clients. Opportunistic contacts were in varied locations such as the family support agency office, hospital, community agencies and shopping centres.

PSWs developed a variety of strategies to visit parents, recognising that they needed to adapt quickly to where parents were located, visiting in a variety of community areas due to convenience or necessity, such as risk of domestic violence at home. This demonstrated their ability to be reflexive to family needs, delivering timely and effective support.

Because we know the mum was a still there (hospital) we thought maybe it would be a good opportunity to touch base. (PSW)

Sit down with them elsewhere, some of them like just to get out of the house. (PSW)

I'll be taking them to art and craft and that's our home visit there. (PSW)

Due to their ethnicity and lived experience in the local community, the PSWs had empathy for Aboriginal families (Author A et al. 2016) which, at times, caused PSW stress.

They're wanting more you know and that's just something we can't do and that's very heartbreaking because we know what it's like to be homeless. (PSW)

It was important for them to have education and training to develop suitable, realistic and acceptable parent support strategies. There were four attributes and strategies identified as important enabling elements of this support.

This article is protected by copyright. All rights reserved. 


\section{Capabilities, strengths and persistence}

Emerging PSW confidence and capabilities progressed with time, during repeated home visiting and reflective practice during action learning sets. Early years and family support education by the child health nurse researcher enhanced their abilities and knowledge of when to refer parents to professional support services. This helped to establish confidence and self-esteem in their role of providing effective support.

Well I was nervous at first. Then I got up and thought here's a go, I've got to do whatever. Afterward I went "yes!", I finally got my first one. But I was really happy, oh my gosh I did it. $(P S W)$

Well since I've been in the role I've found out that I'm very passionate about working with the community. And I love working with families. (PSW)

I always say I'm not the professional but I can always link you up with this person that may be able to help. (PSW).

Persistence in locating families was a key feature of effective PSW practice. As members of the local community, PSWs recognised influences impacting on families' abilities to engage with services, such as transience and family issues. They understood the need to persevere with home visits, attempting to engage with parents when they were not easy to locate. Frequently government and non-government agencies had policies of ceasing contact if parents were not found after two or three attempts.

(Making client contact). Normally services ceased with mainstream agencies. This is pretty much the fourth time for us. (PSW)

However, it was noted that PSW background and prior life experiences may affect their ability to work with parents.

This article is protected by copyright. All rights reserved. 
How does life experience colour people's ability to interact, engage, work, trust, how to function well and find balance. How do we educate PSWs with poor prior education and adverse impacting life experiences? (Agency manager)

Although the PSW's lived experiences as parents were considered to be a positive aspect, their employment with no prior educational parenting support skills was viewed as challenging by some of the family support agency staff.

\section{Communication}

Successfully working and connecting with families was dependent on effective communication strategies, ranging from phone, text and face to face contact. PSWs understood the importance of making connections in a variety of settings and maintaining respectful communication with clients. Persistence with client engagement remained a feature.

If I can't get hold of a client, I will just message and say hello, how are you going, this is me again. $(P S W)$

Keeping in contact, we use texting and phone calls. It shows we're interested. (PSW)

PSWs realised the importance of non-judgemental communication with parents, working from a strengths based approach. They recognised the empowering capacity of praise in their home visiting strategies.

It's easy to judge and assume but we are human beings. We're peer support workers and not here to judge. (PSW)

When they're praised, they like that. We're making clients stronger, helping them to find their voice so they can change. (PSW)

We're not there to point out all their negative things, we're there to praise. (PSW)

This article is protected by copyright. All rights reserved. 


\section{Safe home visiting practices}

An important feature was for PSWs to understand safe home visiting practices, including setting boundaries for client visiting. Proactive risk assessments were undertaken.

The conflict of interest is the main thing to ask about and the level of risk...that will come down to if it's a domestic violence situation or drugs or alcohol, mental health. (Program manager)

Strategies for encouraging PSWs to identify kinship issues were essential, in addition to developing suitable communication and referral pathways when clients contacted them out of hours. This was a sensitive issue needing practice with wording during action learning sets, assisting PSWs to develop culturally appropriate and respectful ways of addressing these situations.

It was even hard for me to tell her, hang on sis it's after work hours. She's always had my personal phone numbers. (PSW)

Is it ok if I come in or ring you if I need someone to talk to? (Parent) I said well that's fine you know I said but not after work hours. (PSW)

\section{Awareness of parent and child issues}

Through their own parenting knowledge and the program's education topics presented by the child health nurse researcher, emergent PSW capabilities in physical and psychosocial family developmental health were developed, such as enhancing child development and safety, family relationships and attachment.

...how we were looking at ways parents can make their own things and how do those things, playing with those toys help with their development. (PSW)

This article is protected by copyright. All rights reserved. 


\section{Responding to impacts of social determinants of health}

Social determinants of health impacted on PSWs', community agencies' and parents' relationships, and provision of support, influencing program activities and development of client self-management and coping strategies. The dominant determinant was lack of housing, generating family stress and fragmentation.

I said the women's shelter has got a vacancy, but they can only help you (mother - not father). (PSW)

There's overcrowding (homes), lack of housing leading to homelessness and couch surfing. Then they can't get baby items as there's nowhere to put them. When housing arrives, all the baby purchases are done at the last minute and that puts a strain on the budget. (Community agency)

Legal issues, illicit substances, mental health and transport all challenged PSW practice. PSWs and community agencies understood the importance and implications of these for families without judgement.

She's a mother of five you know, partner's in jail and she just struggles. She's got the three little ones under three... and no transport. (PSW)

It's hard to do education with mums taking drugs and alcohol. They're not in a good place to take on what we say and do it. (PSW)

There's alcohol, drugs, looking after kids, proper housing, single mums, domestic violence, partners in jail. (PSW)

Yeah she's bipolar. So there's mental health issues. Depression and things like that. (PSW) Also family violence. About $35 \%$ admit to it. It is underreported. (Community agency) 
At times PSWs appeared overwhelmed by these situations, but during reflective practice sessions were able to identify their practice strengths and collaboratively develop meaningful and empathic strategies.

They're wanting more and that's just something that we can't do and that's very heartbreaking because we know what it's like to be homeless...we'll talk about it at each other's desk...we all know our strength and weaknesses and just help each other. (PSW)

Parent responses highlighted PSW understanding of the impacts of social determinants of health on families' lives. The two parents perceived the support as being suitable and effective for their needs, which was underpinned by PSWs being aware and empathetic of issues such as lack of transport impacting on parents' ability to nurture their children.

(PSW) also helping me get my driver's licence. That will be a big help. (Parent 1)

Like, kid wise, for appointments and that, they're there to help me. (Parent 2)

\section{Client support and engagement}

This theme highlighted three sub-themes: Availability of culturally relevant client support; Client engagement; and Client acceptance of PSWs. Various engagement strategies were necessary to provide culturally relevant client support, particularly with ongoing visiting. This issue was recognised by PSWs and agencies who collaborated whenever possible to maintain client contact.

\section{Availability of culturally relevant client support}

Agencies and PSWs identified challenges for families in providing parent support, along with issues in locating suitable community agencies to help them.

Parenting is tough, but depends on who parents are linked in with. (Community agency)

This article is protected by copyright. All rights reserved. 
There is lack of support from families and partners. The mothers don't know which agencies or who to go to for their needs. (Community agency)

Parenting - there's a lack of role models. Clients not knowing what to expect. (Community agency)

The availability and ability of PSWs to work with family members in a culturally appropriate manner was recognised as a strength, highlighting their ability to develop effective relationships.

With Aboriginal families, the family relationship is everything. The PSW's agency is committed to a culturally appropriate service. (Community agency)

On our first visits, we give books. It's a question of giving stuff as a credibility issue. (PSW)

\section{Client engagement}

The willingness and ability of PSWs to engage with parents in a variety of settings demonstrated their skills in developing flexible approaches with clients. This engagement facilitated trusting relationships shown through clients' willingness to yarn which is a feature of culturally secure practice (Bessarab, 2010).

(PSW) is going in to art classes at (the agency). She'll be yarning while doing this. Powerful conversations. (PSW)

I see that PSWs are building relationships through activities. (Community agency)

We do yarning time in the car...we take her to speech therapy. She's reconnecting with services with encouragement. (PSW)

PSWs demonstrated their ability to work in partnership with community agencies to enhance client outcomes, demonstrating an effective and viable approach for the program. 
PSWs can work with our clients as they have time and can reinforce what we are doing. (Community agency)

Structural and psychosocial barriers to home visiting impacted on the PSW's ability to effectively engage with parents. Frequently, clients were too busy with everyday activities such as attending government assistance meetings and family obligations.

They're busy or it's not a good day. (PSW)

Additionally, issues such as mental health influenced client planning for PSW visits or their willingness to open their doors.

Some days she wouldn't open the door. (PSW)

At times, program resources challenged their ability to effectively engage with clients.

Only one car. Often the car's not available when the clients are. This gets in the way of developing relationships with them. (PSW)

Time was needed to develop client relationships and outcomes, highlighting the need to recognise this crucial factor in program planning.

People need to realize that we can't fix things quickly. This is not a quick fix program. It's a "walk with me". (Community agency)

It takes time to build up confidence that this program is valuable. But time can be a challenge. (Community agency)

This article is protected by copyright. All rights reserved. 


\section{Client acceptance of PSWs}

PSW attributes and strategies, along with their engagement approaches, contributed to client acceptance of their visiting support. Following initial apprehension from some parents, a sense of trust was developed over time, indicating acceptance of the PSW support strategies.

They're still sussing us out, still thinking are these mob alright? (PSW)

Her body language to me that morning was definitely a little bit more relaxed. She was more responsive. $(P S W)$

I wouldn't hear anything from her and after the break I sent her a message... and she messaged me back and she was like I need some stuff. (PSW)

This sense of trust and acceptance was confirmed in the responses from both parents, who were wary of their neighbourhoods and government agencies.

Some people are good, some snobby. At school some make you feel low about yourself. (Parent 1)

She (neighbour) rang the police trying to get the police to take her (daughter) off me. (Parent 2)

However, they accepted the PSWs, allowing them to come into their homes. PSW communication skills were a feature of the relationships that developed.

She comes around and phones. It's good to have another adult to talk to. Just talking. (Parent 1)

They're both good listeners. (Parent 2)

This article is protected by copyright. All rights reserved. 


\section{Interagency collaboration}

Working together with community agencies was integral to effective parent support, with PSWs reciprocating to both refer and take referrals for clients. Maintaining interagency contact was important for program visibility, collaboration and effectiveness and to update on agency services.

It was a network meeting... a sharing of the information of services. Just provides us with opportunities to link. (PSW)

The more the word is spread about the program, getting that voice out there again and again. You just have to become an absolute itch that someone has to keep scratching, they (agencies) have to see you. (PSW)

Partnerships with community agencies enabled improved use of resources, effectively enhancing client and staff outcomes.

I can get them (PSWs) to do the home visiting and I can do the parenting over the phone. (Community agency)

Three child protection cases were closed due to our workers' involvement (Program manager)

You need to work together, it's too huge because you burn out. (Community agency)

Challenges to interagency collaboration usually stemmed from service duplication, highlighting a need for clear communication processes between PSWs and agencies.

We just don't want to be duplicating services, I think she's involved with (other agency) again. (PSW)

We tend to get double up on clients because the client doesn't tell you. (Community agency)

This article is protected by copyright. All rights reserved. 


\section{Issues addressing program sustainability}

This theme contained two sub-themes: Funding; and Management governance, which influenced program sustainability.

\section{Funding}

Ongoing sustainability of the parent support initiative was viewed as important by PSWs and community agencies and was an ever present source of anxiety. Secure government funding over a period of time was considered essential for program development, as support services at times were costly.

For Indigenous families, it takes top dollar to reach them. (Community agency)

Financial stability was an issue affecting PSW contracts, resourcing and the ability of the employing family support agency to sustain support.

Funding and funding cuts an issue (Community agency and program manager)

\section{Management governance}

Management governance was also viewed as a factor of program sustainability, including staff retention. Funding for a car and child-safe car seats were budget items in the parent support initiative, however, the car was not purchased until several months after the program commenced. PSWs were aware at commencement of employment that they were required to use their own cars, but this was not sustainable due to irregular car access, roadworthiness and petrol costs. Additionally, following the loss of the existing car seat and need for new booster seats that were safety compliant, replacements were slow to arrive. All these issues were viewed as barriers to accessibility and timely implementation of the program.

And now we've got the car and we've got the car seats. We've finally got the car seats now. So that took ages but finally got 'em. (PSW)

This article is protected by copyright. All rights reserved. 
Only one car. We need to look at how we can use it better. (PSW)

As with their Aboriginal parents, PSWs are members of a vulnerable population group. Accordingly, there were cultural obligations impacting on their availability for work. There was reported and observed tension between PSWs and managers in relation to flexible work policies.

\section{Discussion}

Multiple factors, including PSW home visiting skills, responding to impacts of social determinants of health, client support and engagement, interagency collaboration and issues addressing program sustainability have been found to influence the development of Aboriginal parent support in a Western Australian urban setting. Authors A \& B (2015) have previously demonstrated key characteristics for implementing a culturally secure Aboriginal led home visiting child health parent support program in remote communities. One of the aims of this study was to work with community agencies, PSWs and Aboriginal parents in an urban setting to explore the extent to which similar and different characteristics emerged from the narratives with all participants. This paper contributes evidence from PSWs and community agencies which is supported by parent responses. These data have the potential to inform a model of practice partnership between these three groups and community child health nurses, thereby adding to the body of knowledge on effective and acceptable support programs.

Participants highlighted five themes contributing to the emerging culturally secure suitability, feasibility, acceptability and effectiveness of the home visiting program. It was recognised that, at times, visiting and support could be more effectively undertaken in venues other than homes due to determinants such as parent and PSW safety and shared activities with other community agencies. Similarly, the importance of alternative outreach activities in isolated 
settings was also identified in a remote area study (Author B, 2010). Bowes and Grace (2014) highlight that program engagement is strengthened when conducted in places perceived as safe and where participants feel a sense of ownership and control.

Adverse social determinants of health and varying availability of culturally relevant client support were recognised as impacting on Aboriginal parents' abilities to nurture their families and enhance positive social and emotional wellbeing (Australian Government, DoH, 2013; Milroy, 2014) which has associations with feelings of cultural, family and community connectedness (Government of WA, DoH, 2015, Milroy et al., 2014). PSW empathy and feelings of mutuality are corroborated by Author A et al. (2016), with this insight supporting their attributes and strategies when visiting parents. These were underpinned by ongoing education and training sessions facilitated by the community child health nurse researcher (Author A et al., 2016, Author B, 2010), where acceptable capabilities, strengths and persistence in flexible home visiting approaches and communication were developed and supported by emergent PSW facilitation of physical and psychosocial family developmental health.

Client engagement was enhanced culturally with the ability of PSWs to work with all Aboriginal and non-Aboriginal family members, in addition to community agency linkage. This enabled a partnership approach to practice which was reflective of local culture and worldview belief systems, ultimately informing acceptable and relevant models of care. This was previously reported by Hart (2010) in a study of a research paradigm based within Indigenous worldviews and ways of being. Complex family, health and societal issues influenced the PSWs' liaison with parents, resulting in a scarcity of evidence based responses (Scougall, 2008; Walker \& Shepherd, 2008; Shepherd \& Walker, 2008). However, opportunistic and planned contact along with a range of acceptable communication strategies assisted with these issues in the current study.

This article is protected by copyright. All rights reserved. 
Education and training needs and program sustainability influenced successful program elements and ultimately the development of an ongoing model of care. PSWs identified the value of continuing role development support including current parenting information, learning the process of home visiting, development of communication skills and role play, with mentoring being an important aspect of putting these learnings into action (Author B, 2010).

Factors impacting on the program's implementation and maintenance have been previously recognised by Scougall (2008), including lack of recurrent program funding, infrastructure shortages, management of PSW employment and challenging social environments for both parents and PSWs. Additionally, Shepherd and Walker (2008) and Dudgeon et al. (2014) identified that racism, lack of resources and lack of cultural competence of organisations and practitioners also impact on program effectiveness. However, the five key strategies for Aboriginal parent support proposed by Price-Roberston and McDonald (2011) have been incorporated into the home visiting strategies, contributing substantially to the program's emerging suitability, feasibility, acceptability and effectiveness. These are supported by the recommendations from Flaxman et al. (2009) for culturally appropriate services. With adversity in the early years posing risks of embedding lifelong vulnerabilities (Shonkoff et al., 2009) and the effectiveness of primary prevention approaches for families being increasingly recognised (Mildon \& Polimeni, 2012), there are acknowledged benefits from the perspectives of all study participants of the peer-led home visiting support.

\section{Limitations}

Due to discrete cultural differences between Aboriginal communities, there may be limitations associated with transferability of all findings to other settings. However, there is capacity for elements of the study's findings to be applied to other communities. As 
acknowledged in the literature, engagement issues with Aboriginal clients through problems such as mental health, mobility and family issues (Rosenthal \& Khalil, 2010; Zubrick et al., 2014) reduced data that may have further informed this study's aims. Only two parents were available for interviews. However, the parents' descriptive responses are given credence as they align with data from the PSWs who are parents themselves and living on the same community as the families. Two of the criteria for employment were that the PSWs lived in the same community as the participants and were parents of young children themselves. It is acknowledged that no one can claim complete understanding of another's lived experiences. However, every effort was made in the development and implementation of the program for PSWs to engage with parents with feelings of mutuality and respect, enhancing the ability of parents to discuss personal sensitive issues (Author A et al., 2016). We propose that the findings from this study can inform other environments relating to peer-led home visiting support for other Australian and international Aboriginal communities.

\section{Conclusion}

Parents, PSWs and community agency workers have identified positive aspects of the peerled home visiting child health parent support. The program's suitability, feasibility, acceptability and effectiveness were described across a range of psychosocial environments by PSWs and community agencies, with supporting evidence given by a small number of parents. The key elements and challenges related to culturally nurturing support for Aboriginal families and children have been highlighted. These are crucial for ongoing program and PSW role development, ultimately informing an emerging culturally secure and meaningful model of support.

Currently, and over time, this early intervention strategy will positively enhance lifelong family environments for parents and children in this Western Australian setting and 
potentially other diverse settings as well as across health, education and community services sectors. Despite the importance of family functioning within government policy and reporting contexts, there remain few studies and data sources of Aboriginal programs that utilise robust and relevant Aboriginal informed measures of family functioning to inform or evaluate the effectiveness of policies and programs that aim to improve family and early child health and wellbeing outcomes.

\section{Relevance to Clinical Practice}

Although numerous challenges impact on the development and implementation of a peer-led Aboriginal home visiting parent support program, enabling factors have been identified that are facilitating culturally responsive, acceptable approaches to program development and peer support. Of note is the influence of a partnership approach between community child health nurses, PSWs, community agencies and parents or carers. Key collaborative elements for this significant child health practice role include provision of ongoing PSW role support and education, development of flexible communication strategies for all participants and encouraging a strengths based partnership environment. It is imperative that these are underpinned by acceptable employment practices negotiated between PSWs and their employment agency, secure funding and adequate resources.

Further research is required to incorporate an integrated Aboriginal worldview to understand how to address the complex, interrelated factors influencing family wellbeing and its impacts on early child development. Aboriginal perspectives and experiences are critical in developing programs and services and more culturally relevant indicators of family functioning to measure their effectiveness. Meaningful measures of policy and program effectiveness require collection of information about positive and successful local Aboriginalled initiatives. This, in turn, highlights the importance of using qualitative data and case 
studies to document the more localised and nuanced elements of successful initiatives. These processes would also facilitate the development of an evidence base of key principles and characteristics of successful programs to address complex and interrelated factors that contribute to family functioning and wellbeing in diverse Indigenous contexts. While longitudinal research is recommended to explore the impact of PSW support over a longer period and how effective program can best be supported, the qualitative case study in an urban context described here incorporate both Aboriginal family and organisational perspectives to achieve these aims.

\section{References}

Agree, J. (2009). Developing qualitative research questions: a reflective process. International Journal of Qualitative Studies in Education, 22(4), 431-447. http://dx.doi.org/10.1080/09518390902736512

Australian Government, Department of Health (Australian Government, DoH) (2013). National Aboriginal and Torres Strait Islander Health Plan 2013-2023. Retrieved from : http://www.health.gov.au/internet/main/publishing.nsf/content/B92E980680486C3BCA2 57BF0001BAF01/\$File/health-plan.pdf .

Australian Institute of Health and Welfare (AIHW) (2012). Socioeconomic context of Indigenous health. Retrieved from at: http://www.aihw.gov.au/socio-economic-contextof-indigenous-health/

Author A et al. (2016) Publication details to be provided on acceptance.

Author A et al. (2017) Publication details to be provided on acceptance.

Author A \& Author B (2015) Publication details to be provided on acceptance.

Author B (2010) Publication details to be provided on acceptance.

Bessarab, D. \& Ng'andu, B. (2010). Yarning about yarning as a legitimate method in Indigenous research. International Journal of Critical Indigenous Studies, 3, 37- 50.

Bessarab, D. (2012). Yarning - A culturally safe method of Indigenous conversation. In: Dementia Networking Seminar, Perth, Australia 31 July 2012. Retrieved from http://dtsc.com.au/wp-content/uploads/sites/2/2015/01/Dementia-Yarning-Presentation310712.pdf

Bowes, J., \& Grace, R. (2014). Review of early childhood parenting, education and health intervention programs for Indigenous children and families in Australia. Issues paper no. 8. Produced for the Closing the Gap Clearinghouse. Canberra, ACT: Australian Institute 
of Health and Welfare \& Melbourne: Australian Institute of Family Studies. Retrieved from http://www.aihw.gov.au/uploadedFiles/ClosingTheGap/Content/Our_publications/2014/ ctgc-ip08.pdf

Braun, V., \& Clarke, V. (2006). Using thematic analysis in psychology. Qualitative Research in Psychology 3, 77-101. http://dx.doi.org/10.1191/1478088706qp063oa

Cohen, D., \& Crabtree, B. (2006). Qualitative research guidelines project. Retrieved from http://www.qualres.org/HomeFocu-3647.html

Commissioner for Children and Young People, Western Australia. (2015). "Listen to us". Using the views of WA Aboriginal and Torres Strait Islander children and young people to improve policy and service delivery. Retrieved fromhttps://www.ccyp.wa.gov.au/media/1399/report-atsi-listen-to-us-august-2015.pdf

Department of Communities, Child Safety and Community Services (2013). Queensland Government (2013). Engaging with families. Practice paper. Retrieved from https://www.communities.qld.gov.au/resources/childsafety/practice-manual/ppengaging-with-families.pdf

Department of Health (DoH) (2004). Brief interventions - a definition. Retrieved from http://www.health.gov.au/internet/main/publishing.nsf/Content/Home

Department of the Prime Minister and Cabinet (2014). CfC IPS Performance Report Template. Canberra, ACT: Australian Government.

Department of Social Services (2014). CfC \& CP Performance Review Template. Canberra, ACT: Australian Government.

Dudgeon, P., Cox, A., Walker, R., Scrine, C., Kelly, K., Blurton, D., ...Taylor, N. (2014). Voices of the peoples. The National Empowerment Program. National summary report 2014. Retrieved from http://media.wix.com/ugd/396df4_0442b06dfedb4b309e78623ba9f51ea1.pdf

Dudgeon, P., \& Ugle, K. (2014). Communicating and engaging with diverse communities. In P. Dudgeon, H. Milroy \& R. Walker, R. (Eds.), Working together: Aboriginal and Torres Strait Islander mental health and wellbeing principles and practice $\left(2^{\text {nd }}\right.$ ed., pp. $257-$ 268). Canberra, ACT: Australian Government Department of the Prime Minister and Cabinet. Retrieved from http://aboriginal.telethonkids.org.au/kulunga-researchnetwork/working-together-2nd-edition-2014/

Fereday, J., \& Muir-Cochrane, E. (2006). Demonstrating rigor using thematic analysis: a hybrid approach of inductive and deductive coding and theme development. International Journal of Qualitative Methods, 5, 80-92.

Flaxman, S., Muir, K., \& Oprea, I. (2009). Indigenous families and children: coordination and provision of services. Stronger Families and Communities Strategy 2004-2009. Retrieved from: https://www.dss.gov.au/sites/default/files/documents/op23.pdf

Freemantle, J., Officer, K., McAullay, D., \& Anderson, I. (2007). Australian Indigenous health - within an international context. Perth, WA: Telethon Institute for Child Health

This article is protected by copyright. All rights reserved. 
Research and Onemda VicHealth Koorie Health Unit. Retrieved from https://www.lowitja.org.au/sites/default/files/docs/AustIndigneousHealthReport.pdf

Garner, A. (2013). Home visiting and the biology of toxic stress: opportunities to address early childhood adversity. Pediatrics, 132, S65-S73.

http://dx.doi.org/10.1542/peds.2013-1021D

Government of Western Australia, Department of Health (Government of WA, DoH) (2015), WA Aboriginal health and wellbeing framework 2015-2030. Retrieved from: http://ww2.health.wa.gov.au/Improving-WA-Health/About-Aboriginal-Health/WAAboriginal-Health-and-Wellbeing-Framework-2015-2030 .

Grant, J.G., \& Cadell, S. (2009). Power, pathological worldviews, and the strengths perspective in social work. Families in Society, 90, 425-430. http://dx.doi.org/10.1606/1044-3894.3921

Gray, D., Saggers, S., Atkinson, D., \& Wilkes, E. (2007). Substance misuse. In S. Couzos \& R. Murray (Eds.), Aboriginal primary care: an evidence based approach ( $3^{\text {rd }}$ ed., pp. 755). Melbourne, Vic: Oxford University Press,

Hart, MA. (2010). Indigenous worldviews, knowledge, and research: the development of an Indigenous research paradigm. Journal of Indigenous Voices in Social Work, 1. Online. Retrieved from http://scholarspace.manoa.hawaii.edu/bitstream/handle/10125/15117/v1i1_04hart.pdf?se quence $=1$

Heath, F., Bor, W., Thompson, J., \& Cox, L. (2011). Diversity, disruption, continuity: parenting and social and emotional wellbeing amongst Aboriginal peoples and Torres Strait Islanders. The Australian and New Zealand Journal of Family Therapy, 32, 300313.

Isajiw, WW. (1999). Understanding diversity: ethnicity and race in the Canadian context. Canada: Thompson Press.

Marriott, R., \& Ferguson-Hill, S. (2014). Perinatal and infant mental health and wellbeing. In P. Dudgeon, H. Milroy \& R. Walker (Eds.), Working together: Aboriginal and Torres Strait Islander mental health and wellbeing principles and practice $\left(2^{\text {nd }}\right.$ ed., pp. 337353). Canberra, ACT: Australian Government Department of the Prime Minister and Cabinet.

McEwen, B., Nasveld, P., Palmer, M., \& Anderson, R. (2012). Allostatic load. A review of the literature. Canberra: Department of Veterans' Affairs. Retrieved from: https://www.dva.gov.au/sites/default/files/files/consultation\%20and\%20grants/healthstud ies/allostatic/allostatic.pdf

Mildon. R., \& Polimeni, M. (2012). Parenting in the early years: effectiveness of parenting support programs for Indigenous families. Resource sheet No 16. Retrieved from http://www.aihw.gov.au/uploadedFiles/ClosingTheGap/Content/Publications/2012/ctgcrs16.pdf

Milroy, H. (2014). Understanding the lives of Aboriginal children and families. In Dudgeon, P., Milroy, H., \& Walker, R. (2014). In P. Dudgeon, H. Milroy \& R. Walker (Eds.),

This article is protected by copyright. All rights reserved. 
Working together: Aboriginal and Torres Strait Islander mental health and wellbeing principles and practice ( $2^{\text {nd }}$ ed., pp. 373-381). Canberra, ACT: Australian Government Department of the Prime Minister and Cabinet.

Milroy, H., Dudgeon, P., \& Walker, R. (2014). Community life and development programs pathways to healing. In P. Dudgeon, H. Milroy \& R. Walker (Eds.), Working together: Aboriginal and Torres Strait Islander mental health and wellbeing principles and practice ( $2^{\text {nd }}$ ed., pp. 419-436). Canberra, ACT: Australian Government Department of the Prime Minister and Cabinet.

Neckowaya, R., Brownleea, K., \& Castellana, B. (2007). Is attachment theory consistent with Aboriginal parenting realities? First Peoples Child \& Family Review: A Journal of Innovation and Best Practices in Aboriginal Child Welfare Administration, Research, Policy \& Practice, 3, 65-74.

Preston, R. (2002). Cree narrative (2nd ed.). Quebec: Queen's University Press.

Price-Robertson, R. (2010). Working with Indigenous children, families, and communities. Lessons from practice. CAFCA practice sheet. Retrieved from https://aifs.gov.au/cfca/sites/default/files/publication-documents/ps6.pdf

Price-Robertson, R., \& McDonald, M. (2011). Working with Indigenous children, families, and communities: lessons from practice. CAFCA practice sheet. Retrieved from https://aifs.gov.au/cfca/publications/working-indigenous-children-families-andcommunities

Rogosch, FA, Dackis, MN., \& Cicchetti, D. (2011). Child maltreatment and allostatic load: consequences for physical and mental health in children from low-income families. Dev Psychopathol, 23, 1107-1124. http://dx.doi.org/10.1017/S0954579411000587

Rosenthal, WA., \& Khalil, DD. (2010). Participatory action research in the context of HIV and poverty. Curationis, 33, 69-78.

Sanders, MR., Markie-Dads, C., Tully, LA., \& Bor, W. (2000.) The Triple P - Positive Parenting program: a comparison of enhanced, standard, and self-directed behavioural family intervention for parents of children with early onset conduct problems. Journal of Counselling and Clinical Psychology, 68, 624-640. http://dx.doi.org/10.1037/0022006X.68.4.624

Scougall, J. (2008). Lessons learnt about strengthening Indigenous families and communities. Stronger Families and Communities Strategy 2000-2004. Retrieved from https://www.dss.gov.au/sites/default/files/documents/op19.pdf

Shepherd, C., \& Walker, R. (2008). Engaging Indigenous Parents in Preparing their Children for School. Australian Research Alliance for Children and Youth, ARACY Topical Paper Series. (5 citations) Retrieved fromhttp://www.aracy.org.au/publicationDocuments/TOP_Engaging_Indigenous_Famili es_in_Preparing_Children_for_School_2008.pdf

Shonkoff, J.P., Boyce, WT., \& McEwen, BS. (2009). Neuroscience, molecular biology, and the childhood roots of health disparities: building a new framework for health promotion and disease prevention. JAMA, 301, 2252-9. http://dx.doi.org/10.1001/jama.2009.754

This article is protected by copyright. All rights reserved. 
Tehan, B., \& McDonald, M. (2010). Engaging fathers in child and family services. CAFCA practice sheet. Retrieved from https://aifs.gov.au/cfca/sites/default/files/publicationdocuments/ps2.pdf

Walker, R., \& Shepherd, C. (2008). Strengthening Aboriginal family functioning: What works and why? AFRC Briefing No. 7 Australian Institute of Family Studies. Retrieved from https://aifs.gov.au/cfca/publications/strengthening-aboriginal-family-functioning-whatworks

Wilkes, T. (2014). “Opinion piece - Our Kulunga (children)". The West Australian, 2 June 2014, p.20.World Health Organisation (2015) Social determinants of health. Early child development. Retrieved from http://www.who.int/social_determinants/themes/earlychilddevelopment/en/

Zubrick, S.R., Shepherd, C., Dudgeon, P., Gee, G., Paradies, Y., Scrine, C., \& Walker, R. (2014). Social determinants of social and emotional wellbeing. In P. Dudgeon, H. Milroy \& R. Walker (Eds.), Working together: Aboriginal and Torres Strait Islander mental health and wellbeing principles and practice (2nd ed., pp. 93-112). Canberra, ACT: Australian Government Department of the Prime Minister and Cabinet.

This article is protected by copyright. All rights reserved. 


\section{Tables}

\section{Table 1}

\begin{tabular}{|l|l|}
\hline \multicolumn{1}{|c|}{ Phase } & \multicolumn{1}{c|}{ Description of the process } \\
\hline 1. Familiarising yourself with your data & $\begin{array}{l}\text { Transcribing data (if necessary), reading } \\
\text { and re- reading the data, noting down } \\
\text { initial ideas. }\end{array}$ \\
\hline 2. Generating initial codes & $\begin{array}{l}\text { Coding interesting features of the data in } \\
\text { a systematic fashion across the entire data } \\
\text { set, collating data relevant to each code. }\end{array}$ \\
\hline 3. Searching for themes & $\begin{array}{l}\text { Collating codes into potential themes, } \\
\text { Gathering all data relevant to each } \\
\text { potential theme. }\end{array}$ \\
\hline 4. Reviewing themes & $\begin{array}{l}\text { Checking in the themes work in relation } \\
\text { to the coded extracts (Level 1) and the } \\
\text { entire data set (Level 2), generating a } \\
\text { thematic "map" of the analysis. }\end{array}$ \\
\hline 5. Defining and naming themes & $\begin{array}{l}\text { Ongoing analysis to refine the specifics } \\
\text { of each theme, and the overall story the } \\
\text { analysis tells; generating clear definitions } \\
\text { and names for each theme. }\end{array}$ \\
\hline 6. Producing the report & $\begin{array}{l}\text { The final opportunity for analysis. } \\
\text { Selection of vivid, compelling extract } \\
\text { examples, final analysis of selected } \\
\text { extracts, relating back of the analysis to } \\
\text { the research question and literature, } \\
\text { producing a scholarly report of the } \\
\text { analysis. }\end{array}$ \\
\hline
\end{tabular}

Table 1: Phases of thematic analysis (Braun \& Clarke, 2006, p. 35)

This article is protected by copyright. All rights reserved. 


\section{Table 2}

\begin{tabular}{|c|c|}
\hline Themes & Sub-themes \\
\hline Peer support worker home visiting skills & $\begin{array}{l}\text { Peer support worker education and } \\
\text { training needs } \\
\text { - Peer support worker attributes and } \\
\text { strategies: } \\
\text { ○ Capabilities, strengths and } \\
\text { persistence } \\
\circ \text { Communication } \\
\circ \text { Safe home visiting practices } \\
\circ \text { Visiting flexibility } \\
\circ \text { Awareness of parent and child } \\
\text { issues }\end{array}$ \\
\hline $\begin{array}{l}\text { Responding to impacts of social } \\
\text { determinants of health }\end{array}$ & \\
\hline Client support and engagement & $\begin{array}{ll}\text { - } & \text { Availability of culturally relevant client } \\
\text { support } \\
\text { - } \\
\text { - Client engagement } \\
\text { Client acceptance of peer support } \\
\text { workers }\end{array}$ \\
\hline \multicolumn{2}{|l|}{ Interagency collaboration } \\
\hline Issues addressing program sustainability & $\begin{array}{ll}\text { - } & \text { Funding } \\
\text { - } & \text { Management governance }\end{array}$ \\
\hline
\end{tabular}

Table 2: Themes and sub-themes

This article is protected by copyright. All rights reserved. 